\title{
A More Informative Way to Name Plutonic Rocks- Comment by Frost et al.
}

\author{
B. Ronald Frost, Carol D. Frost, Dept. of Geology and Geophysics, University of Wyoming, Laramie, Wyoming 82071, USA; \\ J. Lawford Anderson, Dept. of Earth and Environment, Boston University, Boston, Massachusetts 02215, USA; Calvin G. Barnes, \\ Dept. of Geosciences, Texas Tech University, Lubbock, Texas 79409, USA; and Marjorie Wilson, School of Earth \& Environment, \\ Leeds University, Leeds LS2 9JT, UK
}

In a recent paper, Glazner et al. (GSA Today, Feb. 2019) proposed a major change in the terminology of plutonic rocks, whereby a simplified rock name is prefixed with the mode. In this classification, a granite might be named 20,20,50 granite. Glazner et al. (2019) proposed this classification system for three reasons. First, they maintain that rock terminology is too complex; they note that at least 157 igneous rock names exist. The second is that the boundaries in the International Union of Geological Sciences (IUGS) classification are arbitrary and hence are confusing when applied to plutonic rock units that show a range in composition. Third, the IUGS system of classification is qualitative, and the quantitative data from which the classification is derived are discarded once the name is determined. To solve these problems Glazner et al. (2019) propose that the petrologic community discard the IUGS classification system and substitute a system with a limited number of rock names that are prefixed by the modal abundance of major phases (such as quartz, alkali feldspar, and plagioclase [QAP] in felsic rocks). They maintain that this is a simpler classification and that it lends itself to a more quantitative classification scheme.

We take exception to Glazner et al.'s (2019) proposal and instead recommend that geologists continue to use the IUGS classification system for naming plutonic rocks. Their first justification, that there are too many obscure terms in igneous petrology, was a problem recognized by the IUGS commission (Streckeisen, 1976; Le Maitre et al., 2002). Hence, the IUGS rock names replaced a plethora of obscure terms. The IUGS classification scheme involves only 55 names for common plutonic igneous rocks. Of these, rocks with $\geq 10 \%$ quartz (the most common group) are described by only 23 names, many of which share the same root name. These names need not be memorized because they are present in the various IUGS diagrams for rock names, a diagram that is easily pasted into field notebooks.

The argument of Glazner et al. (2019) that rock names are determined by "arbitrary" boundaries is not compelling. These boundaries are not arbitrary: The IUGS commission spent many years developing a system that conformed, as much as possible, with existing classification systems. Furthermore, the rock terms have meaning in the sense that geologists know what to expect of a rock described as tonalite instead of granite. Glazner et al. (2019) support their arguments with the observation that two of the plutons in the Sierra Nevada batholith, the Cathedral Peak Granodiorite and the El Capitan Granite, contain rocks that look the same (their Fig. 1). Thus they conclude that the names "granodiorite" and "granite" are in error. However, the error is not in the names of the individual rocks, it is in the assumption that the Cathedral Peak Granodiorite contains only granodiorite whereas the El Capitan Granite contains only granite. Plutons are rarely homogeneous over distances greater than a few tens of meters: they contain rocks with a range of compositions. Whereas each rock named by the IUGS classification is valid, the assumption that the pluton name (i.e., Cathedral Peak Granodiorite) classifies all rocks within the pluton as granodiorite, as implied by Glazner et al. (2019), is simply false.

Glazner et al. (2019)'s third point is that appending numbers that reflect modal abundances to a simple name will result in a more precise description of the rock. This suggestion indicates a confusion of precision and accuracy. Modes are difficult to determine in the field where, as Glazner et al. (2019) observe, the distinction between alkali feldspar and plagioclase can be subtle. Field estimation of modes is unlikely to be better than $\pm 10 \%$. With this precision, a rock classified as a 25,25,40 granite would occupy a large field in the QAP diagram (Fig. 1). For this reason, Streckeisen (1976) suggested a preliminary classification in which granitic rocks may be named with the termination "-oid," as in granitoid. Point-counting a minimum of 1000 points on stained slabs or thin sections produces a more accurate determination of quartz, plagioclase, and alkali feldspar abundances that are used to identify the appropriate IUGS rock name. However, as Glazner et al. (2019) observe, only 5\% of the analyses archived in the NAVDAT database have associated modal data. This means that their quantitative classification system, in addition to being of limited value in the field, is not likely to be widely applied.

A further problem with modal classification is that even when mineral proportions are accurately determined there remains an inherent, irreducible uncertainty. First, the abundance of feldspars in a granitoid is dependent on the cooling history of the rock. A rock that cooled relatively swiftly and contains sodiumbearing orthoclase will have a different ratio of alkali feldspar to plagioclase than one that cooled slowly and contains sodium-poor microcline and plagioclase with sodic rims. Furthermore, crystallization of any muscovite or biotite in a rock will deplete the orthoclase component from the feldspar matrix. Similarly, hornblende crystallization will deplete a 


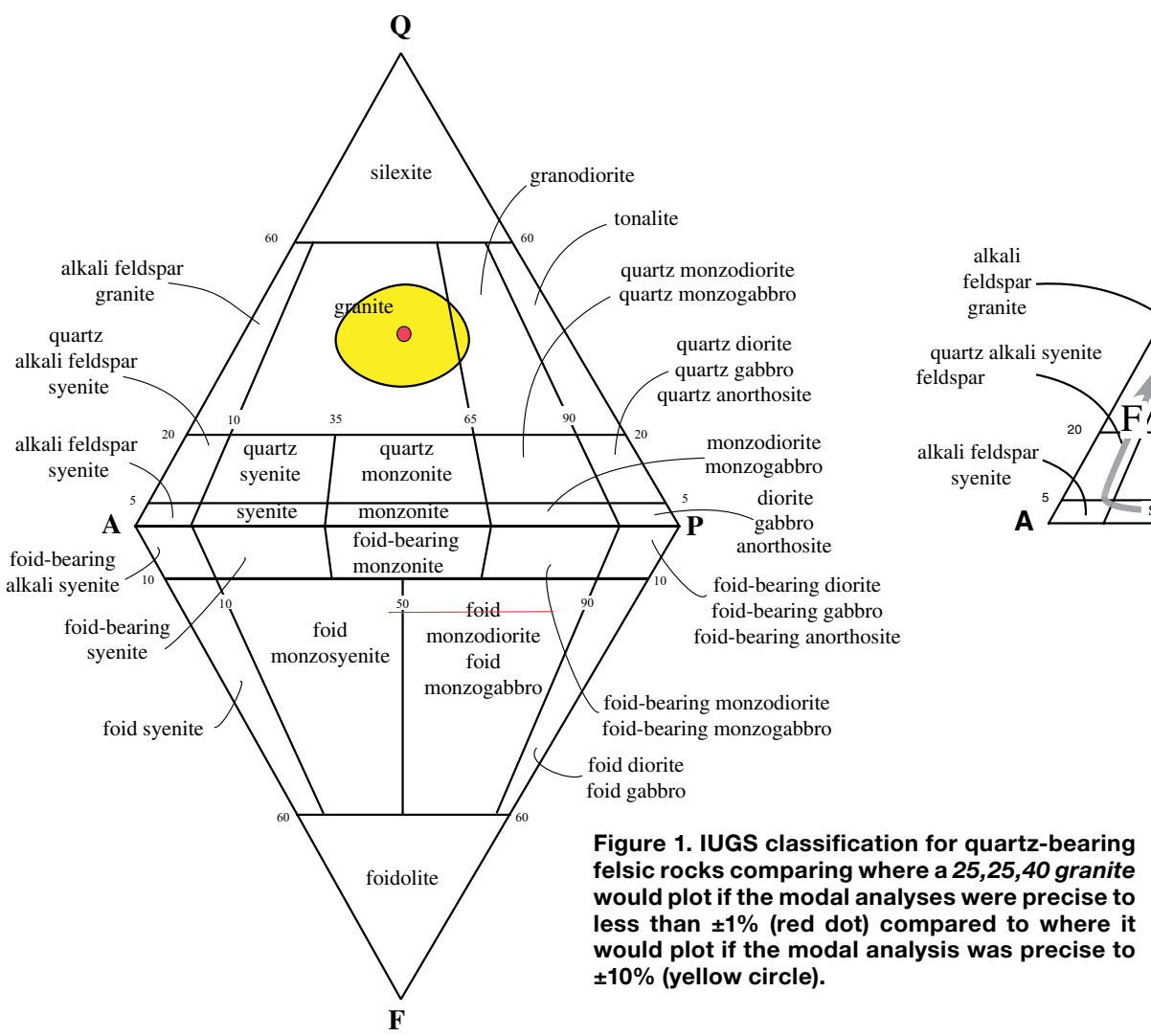

plagioclase component. Any statistical application of a modal classification system would involve these uncertainties.

The IUGS classification bins samples into a relatively small number of rock names to give geologists a general sense of the rock composition. As Streckeisen (1976) puts it, "The system is merely of descriptive character, as it serves to order the rocks that occur in nature according to their mineral content." Moreover, the system allows for modification of the IUGS rock name to make it more informative: a biotite hornblende granodiorite has more hornblende than biotite. A geologist knows that magnetite granite contains $\mathrm{Fe}_{3} \mathrm{O}_{4}$ as the main mafic component of the rock. The prefixes leuco- and mela- may be used to indicate the abundance of mafic minerals in the rock. In addition, the assemblage of IUGS rock names determined from a particular intrusion provides information about magma evolution, which in turn can help identify tectonic setting. For example, a suite of plutonic rocks containing quartz diorite, tonalite, and granodiorite is typical of continental arc batholiths, whereas a suite consisting of monzonite, syenite, quartz syenite, and granite is typical of ferroan granitoids from extensional environments (Fig. 2).

We conclude that it is a mistake to modify the IUGS classification system to make it into a quantitative naming system. The IUGS classification system was developed over nearly 20 years and involved 456 petrologists from 52 countries (Le Maitre et al., 2002). The idea that it should be overturned by a single paper is inadvisable. Glazner et al.'s (2019) proposal to use modes in a quantitative way eliminates rock names that are meaningful and well-established in the geological literature and is burdened by the inherent imprecision of modal analyses. Whole rock chemical analyses are more accurate and reproducible than modes; consequently, as far as quantitative databases are concerned, geochemical databases, coupled with a complete IUGS rock name, provide a better way to
Figure 2. IUGS classification for quartz-bearing felsic rocks showing the differentiation paths followed by various granitic plutons Dashed lines-granitoids of Cordilleran batholiths; CCaledonian batholiths; F-ferroan granites; LG-peraluminous leucogranites; Q-quartz; A-alkali feldspar; P-plagioclase. From Frost and Frost (2014).

quantify rock variability than modes. Together, the IUGS rock names and the corresponding geochemical analyses provide insights into the most important, and frankly most exciting, questions in petrology, including how igneous melts form, how the magmas evolve, and how their compositions reflect the tectonic environments where these processes take place. Let's leave the well-established IUGS classification system in place rather than to try to fix something that is not broken.

\section{REFERENCES CITED}

Frost, B.R., and Frost, C.D., 2014, Essentials of Igneous and Metamorphic Petrology: Cambridge, Cambridge University Press, 314 p.

Glazner, A.F., Bartley, J.M., and Coleman, D.S., 2019, A more informative way to name plutonic rocks: GSA Today, v. 29, p. 4-10, https://doi.org/10.1130/GSATG384A.1.

Le Maitre, R.W., Streckeisen, A., Zanettin, B., LeBas, M.J., Bonin, B., Bateman, editors, 2002, Igneous Rocks: A Classification and Glossary of Terms: Cambridge, Cambridge University Press, https://doi.org/10.1017/ CBO9780511535581.

Streckeisen, A., 1976, To each plutonic rock its proper name: Earth-Science Reviews, v. 12, p. 1-33, https://doi.org/10.1016/0012-8252 (76)90052-0.

ManusCript ReCEIVEd 7 Mar. 2019

MANUSCRIPT ACCEPTED 11 MAR. 2019 